\section{BMJ Paediatrics Open}

\title{
Haematocrit in $<35$ weeks preterm infants who received at least 60 seconds of delayed cord clamping: a retrospective observational study
}

Matthew JR Nudelman, ${ }^{\oplus 1,2,3}$ Keshav Goel, ${ }^{1}$ Priya Jegatheesan, ${ }^{1,2}$ Dongli Song, ${ }^{1,2}$ Angela Huang, ${ }^{1}$ Balaji Govindaswami ${ }^{1,2}$

\section{ABSTRACT}

Objective To describe haematocrit at birth in preterm infants who received $\geq 60$ s of delayed cord clamping (DCC).

Design Retrospective observational study.

Setting A California public hospital with an American Academy of Pediatrics level 4 neonatal intensive care unit, with 3500-4000 deliveries annually.

Participants 467 preterm infants born at $<35$ weeks' gestational age (GA) between January 2013 and December 2018.

Received 12 June 2019 Revised 29 August 2019 Accepted 1 September 2019

\section{Primary and secondary outcome}

measures Haematocrit reference ranges for $0-4$ hours
Check for updates

(C) Author(s) (or their employer(s)) 2019. Re-use permitted under CC BY-NC. No commercial re-use. See rights and permissions. Published by BMJ.

${ }^{1}$ Pediatrics / Newborn Medicine Santa Clara Valley Medical Center: Hospital and Clinics, San Jose, California, United States ${ }^{2}$ Stanford, School of Medicine, Palo Alto, California, United States

${ }^{3}$ University of California, San Francisco, San Francisco, California, United States

Correspondence to Dr Matthew JR Nudelman; matthew.nudelman@hhs. sccgov.org after birth and paired haematocrit differences between $0-4$ and $4-24$ hours.

Methods Haematocrits were obtained when clinically indicated and collected from arterial, venous and capillary sources. Haematocrits obtained after packed red blood cell transfusions were excluded. We summarised the first available haematocrit between 0 and 4 hours by GA strata. We used mixed-effects linear regression to describe the associations between haematocrit and predictor variables including GA, male sex and hours after an infant's birth. We also compared paired haematocrits at $0-4$ and $4-24$ hours after birth.

Results The median GA of the 467 included infants was 33.3 weeks, birth weight was $1910 \mathrm{~g}$ and DCC duration was $60 \mathrm{~s}$. The mean $(95 \% \mathrm{Cl})$ first haematocrit at $0-4$ hours was $46.6(45.0 \%$ to $48.1 \%), 51.2$ ( $49.6 \%$ to $52.8 \%$ ), 50.6 ( $49.1 \%$ to $52.1 \%), 54.3(52.8 \%$ to $55.8 \%$ ) and 55.6 (54.6\% to $56.6 \%)$ for infants $23-29,30-31,32,33$ and 34 weeks' GA strata, respectively. The subanalysis of 174 infants with paired haematocrits at 0-4 and 4-24 hours showed that for each additional hour after birth, the mean $(95 \% \mathrm{Cl})$ haematocrit increased by $0.2(0.1 \%$ to $0.3 \%), 0.2(0.1 \%$ to $0.4 \%)$ and $0.1(0.0 \%$ to $0.2 \%)$ for infants in $23-29,30-31$ and 32 weeks' GA strata, respectively. The subanalysis showed no change between the paired haematocrits in the 33 and 34 weeks' GA strata.

Conclusions Our study describes haematocrit in preterm infants who received $\geq 60 \mathrm{~s} \mathrm{DCC}$ as standard of care. Haematocrit during the first $0-4$ hours in our study is higher than the previously described reference ranges prior to DCC becoming routine clinical practice. The paired second haematocrit at 4-24 hours is higher than haematocrit at $0-4$ hours.
What is known about the subject?

Current haematocrit reference ranges for preterm infants were described prior to delayed cord clamping (DCC) becoming routine clinical practice.

- Newborn haematocrit increases with each gestational age (GA).

\section{What this study adds?}

- This study describes haematocrit reference ranges for preterm infants who received at least $60 \mathrm{~s}$ of DCC.

- There is a greater increase in haematocrit for each GA compared with the previously described references in the pre-DCC population.

- Paired sample analysis showed that DCC increases haematocrit from birth to 24 hours after birth in preterm infants 23-32 weeks' GA.

Preterm infants are born with lower haematocrit than term infants and are at a higher risk for blood transfusion. Studies show delayed cord clamping (DCC) increases placental transfusion and blood volume. ${ }^{12}$ Meta-analyses of more recent studies have shown DCC, compared with early cord clamping (ECC), is associated with higher haemoglobin and haematocrit, higher blood pressure, fewer blood transfusions, reduced intraventricular haemorrhage, and decreased hospital mortality. ${ }^{3}{ }^{4}$ A very large population-based study showed reduced severe neurological injury ${ }^{5}$ in infants 22-28 weeks' gestational age (GA) receiving DCC.

Hooper et at have rightly suggested that the debate on DCC duration shift away from a time-based approach to a physiology-based approach. Placental transfusion benefit, enhanced by infant ventilation, is the first step in the transfer of sufficient iron essential to optimal brain myelination. Term infants who 
had their cord clamped after a mean of $172 \mathrm{~s}$ compared with a control group who had their cord clamped after a mean of $28 \mathrm{~s}$ had higher haematocrit at 48 hours, as well as higher ferritin and evidence of better myelination of the internal capsule and other areas of the brain essential to visual, motor and sensory function/integration at 4 months of age. ${ }^{7}$ Term infants randomised to 3 min of DCC showed improved fine motor/social function, especially in boys at 4 years of age. ${ }^{8} \mathrm{~A}$ randomised controlled trial (RCT) showed preterm infants $<33$ weeks receiving a mean of $32 \mathrm{~s}$ DCC compared with a mean of ECC $6.6 \mathrm{~s}$ had better motor function at 18-22 months corrected age. ${ }^{9}$ In infants $<27$ weeks, areas of the brain responsible for visual motor integration and fine motor skills are known to be particularly vulnerable to injury, with resultant functional deficits noted 6.5 years later. ${ }^{10}$ Effective spontaneous ventilation for optimal cardiopulmonary transition in the majority of very preterm infants appears to occur more than a minute or two after birth; thus, timing is relevant to the physiology of transition. Increased DCC duration may be especially important in extremely preterm infants, where umbilical cord milking is less likely to be a viable alternative for placental transfusion benefit. ${ }^{11}$

The WHO, Neonatal Resuscitation Program, American Congress of Obstetricians and Gynecologists, and other international societies have recommended a minimum duration of DCC of at least 30-60s to improve preterm neonatal outcomes. ${ }^{12-16}$

Previously published haematocrit reference ranges based on GA and time after birth were obtained prior to DCC becoming standard of care. ${ }^{17}$ At our institution, DCC for at least $60 \mathrm{~s}$ has been the standard of care since 2011 . We have previously shown that implementing a minimum of $60 \mathrm{~s}$ DCC in clinical practice increases haematocrit and reduces risk of blood transfusion. ${ }^{18}$ Haematocrit reference ranges for preterm infants who received DCC as standard of care have not been described; the goal of this study is to present haematocrit for preterm infants $<35$ weeks' GA who received at least 60 s DCC.

\section{METHODS}

Design

This is a single-centre, retrospective observational study.

\section{Patient and public involvement}

The study design, analysis and plans to disseminate information from this research were done without patient involvement given this is a retrospective study evaluating DCC and haematocrit which were performed and collected, respectively, as part of our standard of care.

\section{Subjects}

Inborn preterm infants $<35$ weeks' GA admitted to an American Academy of Pediatrics level 4 neonatal intensive care unit (NICU) in 72 consecutive months (January 2013-December 2018) were eligible for inclusion in the study. Infants were excluded if they (1) received less than 60 s DCC or (2) had no recorded haematocrit within the first 24 hours after birth.

\section{Standardised delivery room and initial preterm infant care}

We have established a standardised delivery room management protocol for all preterm infants that includes a minimum of $60 \mathrm{~s}$ of DCC since $2011 .^{19}$ The intended minimum DCC duration was increased to $120 \mathrm{~s}$ and $180 \mathrm{~s}$ in 2016 and 2018, respectively; the minimum intended DCC duration was not performed when there were maternal or neonatal safety concerns. Umbilical cord milking is discouraged at our institution.

\section{Data collection}

Eligible infants were identified from our prospectively maintained NICU database containing maternal and infant demographics as well as neonatal outcomes. Haematocrits were obtained retrospectively from patients' hospital electronic medical record.

\section{Haematocrit}

Complete blood counts (CBCs) were obtained from infants when clinically indicated. Blood samples were obtained from venous, arterial and capillary sources. CBCs between 0-4 and 4-24hours after birth were used for the study. Time points were chosen because CBCs were routinely obtained in our NICU on admission and on follow-up within 24 hours if indicated. Only the earliest haematocrit was included if more than one was recorded during the time intervals. CBCs from arterial, venous or capillary specimens were measured using Beckman Coulter DxH800 from 2013 to 2014 and using Sysmex $\mathrm{XN}-3000$ from 2015 to 2018. Haematocrits either derived from cord blood samples or obtained after packed red blood cell (RBC) transfusion were excluded.

\section{Data analysis}

We used descriptive statistics to describe haematocrit at 0-4hours after birth for each GA stratum. We summarised the first available haematocrit between 0 and 4 hours according to GA strata: 23-29, 30-31, 32, 33 and 34 weeks' GA. GA categories were created to provide detailed haematocrit values for each GA group. Younger infants $<32$ weeks' GA were combined into shared strata due to limited sample size. Regression models were used to describe the associations between newborn haematocrit and predictor variables including GA, male sex and infant age in hours at the time of haematocrit collection. We used multilevel mixed-effects linear regression with clustering around the mother to account for the presence of multiples (ie, twins, triplets) and clustering around infants with paired haematocrits at $0-4$ and 4-24hours. The multilevel mixed-effects linear regression models used restricted maximum likelihoods and unstructured covariance.

Each regression model was assessed for interactions and multicollinearity. Model residuals were assessed for normality, linearity and homoskedasticity. Outliers 


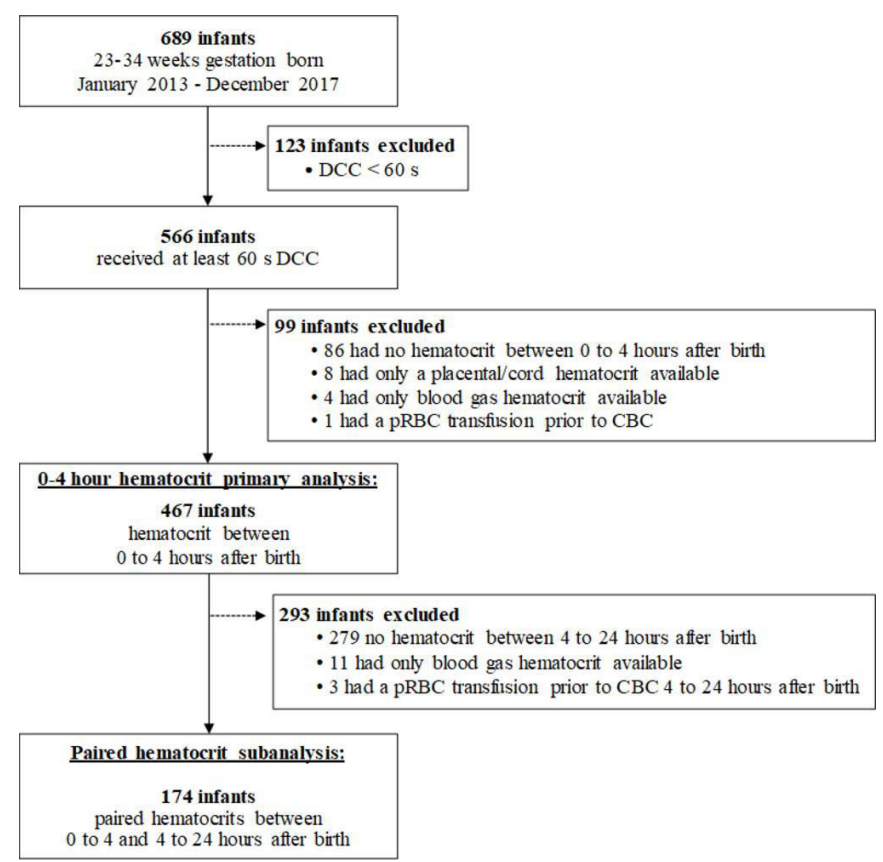

Figure 1 Study subject and data selection. CBC, complete blood count; DCC, delayed cord clamping; pRBC, packed red blood cells.

were evaluated by running each model with and without infants whose residuals were $>2$ SD from the mean. Statistical analysis was performed using STATA V.14.

\section{RESULTS}

\section{Subjects}

A total of 689 infants were born at $<35$ weeks' GA during the study period, of whom $566(82 \%)$ received at least 60 s DCC. Of these 566 infants, $467(83 \%)$ had haematocrit at 0-4 hours (figure 1) used for our primary analysis. For our paired subanalysis, a total of $174(37 \%)$ of the 467 infants were included based on having had an additional haematocrit at 4-24 hours after birth.

\section{Demographics}

Infant and maternal demographics and NICU outcomes are described in table 1 . The median GA was 33.3 weeks (range 23.3-34.9) and birth weight was $1910 \mathrm{~g}$ (range 400-3241). The median DCC duration was 60s (range $60-900)$ and $36 \%$ received greater than or equal to $120 \mathrm{~s}$ DCC.

\section{Haematocrit}

Haematocrits at $0-4$ hours and 4-24 hours were obtained at a median (IQR) age of 0.9 hours $(0.7-1.2)$ and 13 hours (12-19), respectively. There was no difference in DCC duration or age when CBC specimens were obtained between GA strata. Haematocrit at $0-4$ hours increased with each GA stratum (figure 2).

Table 2 shows the associations between newborn haematocrit and predictor variables including GA, male sex and infant age at the time of haematocrit collection. In regression models, GA was positively associated with
Table 1 Infant and maternal demographics

Study cohort $(\mathrm{N}=467)$

n (\%); median (IQR)

\begin{tabular}{lc}
\hline Infant demographics & \\
Gestational age, weeks & $33.3(31.1-34.1)$ \\
Birth weight, g & $1910(1450-2252)$ \\
\hline Delayed cord clamping, s & $60(60-120)$ \\
1 min Apgar* & $8(7-8)$ \\
5 min Apgar* & $9(8-9)$ \\
Male & $252(54)$ \\
Small for gestational age & $41(9)$ \\
Multiples & $92(20)$ \\
\hline Twins & $86(18.5)$ \\
\hline Triplets & $6(1.5)$ \\
Maternal demographics & \\
\hline Caesarean section & $236(51)$ \\
Maternal hypertension & $166(36)$ \\
\hline Maternal diabetes & $95(20)$ \\
\hline Antenatal steroids & $396(85)$ \\
\hline
\end{tabular}

${ }^{*} \mathrm{n}=466$.

haematocrit, as demonstrated by the beta coefficient; haematocrit increases by at least 1.2 for each additional week of gestation.

In models 1 and 2, haematocrit was not associated with either male sex or the infant's age in hours at the time of haematocrit collection.

The subanalysis of the 174 infants with paired samples demonstrated that haematocrits at 4-24hours were higher than those at $0-4$ hours, although only significant for infants $<33$ weeks' GA (table 3 ).

\section{DISCUSSION}

Our single-centre study is the largest cohort of preterm infants receiving at least $60 \mathrm{~s}$ DCC as standard of care with haematocrits in the first 24 hours after birth. We show that the initial haematocrit in preterm infants receiving at least $60 \mathrm{~s}$ DCC increases with GA. At each GA the initial haematocrit (0-4hours) is higher than that previously published in infants prior to DCC becoming routine clinical practice. ${ }^{17}$ Individual paired analysis at $0-4$ and 4-24hours allowed us to illustrate a significant increase in the haematocrit during the first 24 hours after birth in those born $<33$ weeks' GA.

The mean haematocrit at $0-4$ hours in DCC infants in our study was higher for each GA stratum compared with those previously described by Jopling et al. ${ }^{17}$ The mean haematocrit of infants 28-34 weeks' GA in our study was 53.5 , similar to the haematocrit of 53.8 described by Saigal et $a t^{2}$ in their 60s DCC group. A Swiss RCT by Baenziger et $a l^{20}$ similarly observed a mean haematocrit of 55.56 at 4 hours after birth in 15 infants who received 60-90 s 


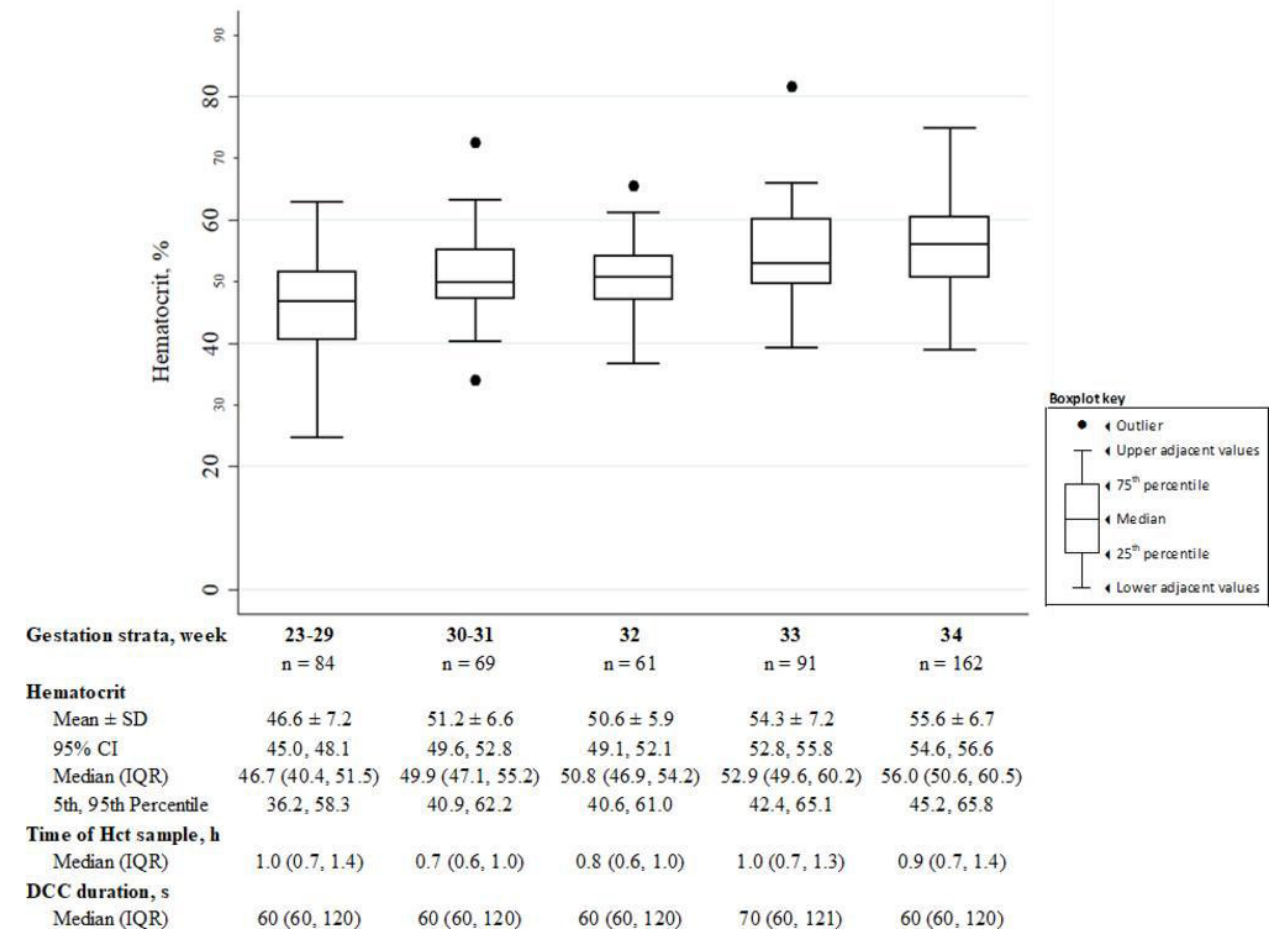

Figure 2 Initial haematocrit (0-4 hours) distribution in gestational age strata. DCC, delayed cord clamping; Hct, haematocrit.

of DCC at $408 \mathrm{~m}$ altitude. While Jopling et $a l^{17}$ showed a $0.64 \%$ increase in haematocrit per week of GA between 22 and 40 weeks, we observed $1.2 \%$ increase in haematocrit per week between 23 and 34 weeks' GA. In our study, the incremental placental transfusion benefit in the first minute of DCC is greater for infants with higher GA compared with those with lower GA. Saigal et al showed that both term and preterm infants who received $5 \mathrm{~min}$ of DCC increased their blood volume by $47 \%$ and $50 \%$, respectively. However, $76 \%$ of this transfusion benefit in term infants occurred in the first minute compared with $56 \%$ in preterm infants. Both our study and Saigal $e t$ $a l \mathrm{~s}^{2}$ study suggest that for a given DCC duration, better cardiopulmonary transition in higher GA infants leads to higher placental transfusion benefit.

In our study, there is no difference in haematocrit between 0 and 4 hours, although $75 \%$ of our samples were collected within 1.2 hours after birth. Jopling et $a l^{17}$ previously reported haematocrit loss of $6 \%$ in the first 4 hours after birth in preterm infants (22-28 weeks' GA) but not in infants 29-34 weeks' GA. This discrepancy in the extremely preterm infants may be explained by practice changes over the last decade, including blood loss prevention.

In our study, within individually paired $0-4$ and 4-24hours haematocrit, analysis showed that haematocrit increased in the first day after birth. Pre-DCC haematocrit reference range study does not show increased haematocrit in the first 24 hours after birth. Our observed increase in haematocrit at 24 hours was not seen in other DCC studies. ${ }^{20}$ Saigal et $a l^{2}$ showed similar haematocrits obtained from DCC infants at 0.5-4hours but no increase at 24 hours. Baenziger et $a t^{20}$ similarly did not observe an increase in haematocrit at 24 hours. The increase in the haematocrit that we observed may be attributable to current clinical practice, including increased DCC duration, less phlebotomy, judicious fluid management and enhanced haemodynamic stability. ${ }^{21}$ Physiological advantages of DCC include improved cardiac output, renal perfusion and enhanced diuresis, leading to haemoconcentration.

Table 2 Two-tiered, mixed-effects regression model with clustering around the mother describing the association between preterm newborn Hct at $0-4$ hours and predictors including gestational age, male sex and infant age in hours at the time of Hct collection $(\mathrm{N}=467)$

\begin{tabular}{llllrr}
\hline Model & Predictors & $\boldsymbol{\beta}$ & $\mathbf{S E}$ & $\mathbf{9 5 \%} \mathbf{C l}$ & P value \\
\hline 1 & Gestational age, weeks & 1.2 & 0.1 & 1.0 to 1.5 & $<0.001$ \\
& Male sex & 0.7 & 0.6 & -0.6 to 1.9 & 0.299 \\
2 & Gestational age, weeks & 1.2 & 0.1 & 1.0 to 1.5 & $<0.001$ \\
& Age at time of $0-4$ hours Hct collection, hours & 0.7 & 0.5 & -0.4 to 1.7 & 0.204 \\
\hline
\end{tabular}

Hct, haematocrit. 
Table 3 Subanalysis of infants with paired Hct at 0-4 and 4-24hours after birth showing that Hct increases over 24 hours in infants $<33$ weeks' gestation $(n=174)$

\begin{tabular}{|c|c|c|c|c|c|c|c|c|}
\hline \multirow[b]{2}{*}{ GA, weeks } & \multirow[b]{2}{*}{ Infants (n) } & \multirow[b]{2}{*}{ Het (n) } & \multirow{2}{*}{$\begin{array}{l}\text { Hct at 0-4 hours, } \\
\text { M (SD) }\end{array}$} & \multirow{2}{*}{$\begin{array}{l}\text { Hct at 4-24hours, } \\
\text { M (SD) }\end{array}$} & \multirow{2}{*}{$\begin{array}{l}\text { Difference, M } \\
\text { (SD) }\end{array}$} & \multicolumn{3}{|c|}{ Adjusted* $^{*}$} \\
\hline & & & & & & $\beta$ & $95 \% \mathrm{Cl}$ & $P$ value \\
\hline $23-34$ & 174 & 348 & $51.5(8.5)$ & $53.6(8.6)$ & $2.1(5.7)$ & 0.1 & 0.1 to 0.2 & $<0.001$ \\
\hline 23-29 & 50 & 100 & $46.4(6.9)$ & $49.2(8.1)$ & $2.8(6.1)$ & 0.2 & 0.1 to 0.3 & 0.003 \\
\hline $30-31$ & 28 & 56 & $50.9(8.0)$ & $55.1(9.0)$ & $4.2(4.9)$ & 0.2 & 0.1 to 0.4 & $<0.001$ \\
\hline 33 & 33 & 66 & $55.2(8.9)$ & $55.3(8.7)$ & $0.1(6.6)$ & 0 & -0.2 to 0.2 & 0.980 \\
\hline 34 & 33 & 66 & $57.3(7.8)$ & $58.1(7.2)$ & $0.9(5.2)$ & 0 & -0.1 to 0.2 & 0.644 \\
\hline
\end{tabular}

${ }^{*}$ Three-tiered, multilevel, mixed-effects linear regression model adjusted for gestational age and clustered by mother and infant.

Hct, haematocrit.

Our study has several limitations. Blood samples were obtained from arterial, venous and capillary sources. It is known that capillary haematocrits are higher than venous haematocrits. ${ }^{22} 23$ Our single-centre study with $84 \%$ antenatal steroid exposure includes better prepared preterm infants whose cardiopulmonary physiology would enhance placental transfusion benefit. We excluded $18 \%(123 / 689)$ of preterm infants who did not receive the intended $60 \mathrm{~s}$ duration of DCG due to maternal or neonatal indications. This selection limits our generalisability to all preterm infants $<35$ weeks' GA. We also excluded an additional $15 \%$ (99/689) of infants primarily due to unavailable haematocrit at $0-4$ hours. We suspect most of these excluded infants were clinically stable and early newborn labs may not have been indicated or necessary; thus, they may have been healthier than those included in the study. Less than $37 \%$ (174/467) of our cohort had a second haematocrit available, which could cause selection bias. In practice, less stable infants are more likely to have a second recorded haematocrit within 24 hours. This bias is likely to underestimate the increase in haematocrit in the first day after birth and may explain the lack of significant increase in haematocrit in infants 33-34 weeks' GA.

Our study could have additional utility by providing similar metrics and analysis for haemoglobin. Although haematocrit and haemoglobin are highly correlated and regularly used to assess anaemia, conversion between them is not ideal. Haematocrit is indirectly calculated from the product of the RBC count and mean corpuscular volume, whereas haemoglobin is measured spectrophotometrically. Two different haematology analysers were used during this study, which introduces intermachine variability into our estimates. However, these two analysers have been shown to exhibit good haematocrit agreement and high correlation $(r>0.985) .{ }^{24}$ Furthermore, the results of the regression analysis are unlikely to be biased because the analysers were not preferentially used across GAs, and the same analyser presumably was used for paired haematocrits.
In conclusion, we present a haematocrit reference range for preterm infants who receive at least $60 \mathrm{~s}$ DCC as part of standard of care. There is a greater increase in haematocrit for each GA compared with the previously described references in the pre-DCC population. ${ }^{17}$ Paired sample analysis showed that DCC increases haematocrit from birth to 24 hours after birth in preterm infants 23-32 weeks' GA.

Acknowledgements We express gratitude to our patients and families. This work would not be possible without the extreme dedication of SCVMC NICU and Labor and Delivery nursing staff, respiratory therapists, neonatal nurse practitioners, neonatologists, neonatal hospitalists, NICU database team, obstetricians, perinatologists, Stanford University paediatric house staff and SCVMC obstetric house staff, and Santa Clara County First 5 and Valley Medical Center Foundation. We thank MN's clinical research mentors, Hilary Seligman, MD MAS, Thomas Newman, MD MPH, and Isabel E Allen, PhD, for their guidance.

Contributors BG, PJ and DS conceptualised the study. BG, PJ, DS, MN and AH designed the study. MN, KG and AH performed the data collection. MN, KG and PJ designed and ensured valid data collection. MN, KG and PJ carried out the data analysis. MN, KG and PJ drafted the initial abstract and the manuscript. All authors critically reviewed and revised the manuscript. All authors approved the final manuscript as submitted and agree to be accountable for all aspects of the work.

Funding The authors received funding support for data collection for this study from Santa Clara County First 5.

Competing interests None declared.

Patient consent for publication Not required.

Ethics approval This study was approved as a quality improvement project by the Institutional Review Board.

Provenance and peer review Not commissioned; externally peer reviewed. Data availability statement Data are available upon reasonable request.

Open access This is an open access article distributed in accordance with the Creative Commons Attribution Non Commercial (CC BY-NC 4.0) license, which permits others to distribute, remix, adapt, build upon this work non-commercially, and license their derivative works on different terms, provided the original work is properly cited, appropriate credit is given, any changes made indicated, and the use is non-commercial. See: http://creativecommons.org/licenses/by-nc/4.0/.

\section{REFERENCES}

1. Yao AC, Lind J, Tiisala R, et al. Placental transfusion in the premature infant with observation on clinical course and outcome. Acta Paediatr 1969;58:561-6.

2. Saigal S, O'Neill A, Surainder $Y$, et al. Placental transfusion and hyperbilirubinemia in the premature. Pediatrics 1972;49:406-19. 
3. Rabe H, Diaz-Rossello JL, Duley L, et al. Effect of timing of umbilical cord clamping and other strategies to influence placental transfusion at preterm birth on maternal and infant outcomes. Cochrane Database Syst Rev 2012;8.

4. Fogarty M, Osborn DA, Askie L, et al. Delayed vs early umbilical cord clamping for preterm infants: a systematic review and meta-analysis. Am J Obstet Gynecol 2018;218:1-18.

5. Lodha A, Shah PS, Soraisham AS, et al. Association of deferred vs immediate cord clamping with severe neurological injury and survival in extremely Low-Gestational-Age neonates. JAMA Netw Open 2019;2:e191286.

6. Hooper SB, Binder-Heschl C, Polglase GR, et al. The timing of umbilical cord clamping at birth: physiological considerations. Matern Health Neonatol Perinatol 2016;2.

7. Mercer JS, Erickson-Owens DA, Deoni SCL, et al. Effects of delayed cord clamping on 4-month ferritin levels, brain myelin content, and neurodevelopment: a randomized controlled trial. $J$ Pediat 2018;203:e262:266-72.

8. Andersson $\mathrm{O}$, Lindquist $\mathrm{B}$, Lindgren $\mathrm{M}$, et al. Effect of delayed cord clamping on neurodevelopment at 4 years of age: a randomized clinical trial. JAMA Pediatr 2015;169:631-8.

9. Mercer JS, Erickson-Owens DA, Vohr BR, et al. Effects of placental transfusion on neonatal and 18 month outcomes in preterm infants: a randomized controlled trial. J Pediatr 2016;168:e51:50-5.

10. Bolk J, Padilla N, Forsman L, et al. Visual-motor integration and fine motor skills at $61 / 2$ years of age and associations with neonata brain volumes in children born extremely preterm in Sweden: a population-based cohort study. BMJ Open 2018;8:e020478.

11. Katheria $A C$, Reister $F$, Hummler $\mathrm{H}$, et al. Lb 1: premature infants receiving cord milking or delayed cord clamping: a randomized controlled non-inferiority trial. Am J Obstet Gynecol 2019;220:S682.

12. Leduc D, Senikas V, Lalonde AB, et al. Active management of the third stage of labour: prevention and treatment of postpartum hemorrhage. J Obstet Gynaecol Can 2009;31:980-93.

13. WHO. Guideline: delayed umbilical cord clamping for improved maternal and infant health and nutrition outcomes 2014.

14. Wyckoff MH, Aziz K, Escobedo MB, et al. Part 13: neonatal resuscitation: 2015 American heart association guidelines update for cardiopulmonary resuscitation and emergency cardiovascular care (reprint). Pediatrics 2015;136(Supplement):S196-218.

15. Delayed umbilical cord clamping after birth. Pediatrics $2017 ; 139$.

16. Sweet DG, Carnielli V, Greisen G, et al. European Consensus Guidelines on the Management of Respiratory Distress Syndrome 2016 Update. Neonatology 2017;111:107-25.

17. Jopling J, Henry E, Wiedmeier SE, et al. Reference ranges for hematocrit and blood hemoglobin concentration during the neonatal period: data from a multihospital health care system. Pediatrics 2009;123:e333-7.

18. Song D, Jegatheesan P, DeSandre G, et al. Duration of cord clamping and neonatal outcomes in very preterm infants. PLoS One 2015;10:e0138829.

19. Manani M, Jegatheesan P, DeSandre G. Elimination of admission hypothermia in preterm very low-birth-weight infants by standardization of delivery room management. Perm $\mathrm{J}$ 2013;17:8-13.

20. Baenziger O, Stolkin F, Keel M, et al. The influence of the timing of cord clamping on postnatal cerebral oxygenation in preterm neonates: a randomized, controlled trial. Pediatrics 2007;119:455-9.

21. Govindaswami B, Nudelman M, Narasimhan SR, et al. Eliminating risk of intubation in very preterm infants with noninvasive cardiorespiratory support in the delivery room and neonatal intensive care unit. Biomed Res Int 2019;2019:5984305-14.

22. Christensen RD. Expected Hematologic Values for Term and Preterm Neonates. In: Christensen RD, ed. Hematologic Problems of the Neonate. The University of Michigan: W.B. Saunders Company, 2000: 117-36.

23. Linderkamp O, Versmold HT, Strohhacker I, et al. Capillary-Venous hematocrit differences in newborn infants. I. Relationship to blood volume, peripheral blood flow, and acid base parameters. Eur $J$ Pediatr 1977;127:9-14.

24. Genc S, Dervisoglu E, Erdem S, et al. Comparison of performance and abnormal cell flagging of two automated hematology analyzers: Sysmex XN 3000 and Beckman Coulter DxH 800. Int J Lab Hematol 2017;39:633-40. 